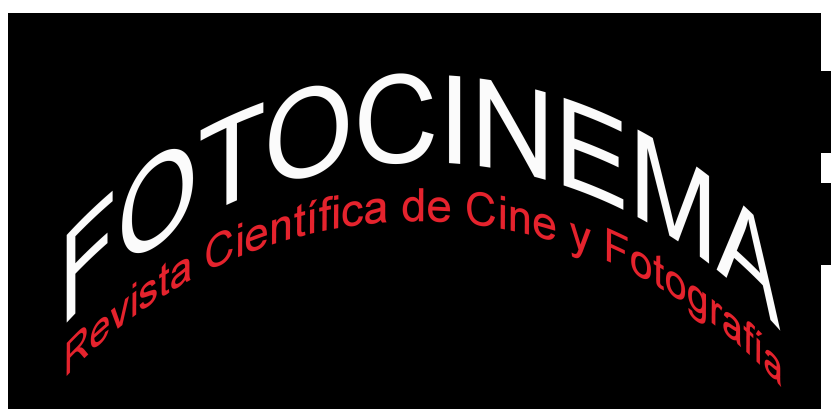

Recibido 04-03-2015 / Aceptado 13-03-2015

/ Publicado 19/07/2015

\title{
DE LA ENTREVISTA AL BIOPIC. ANDRZEJ WAJDA, WALESA: MAN OF HOPE (2013)
}

\section{FROM THE INTERVIEW TO THE BIOPIC. ANDRZEJ WAJDA, WALESA: MAN OF HOPE (2013)}

Fermín Galindo Arranz

Universidad de Santiago de Compostela, España fermin.galindo@usc.es

\section{Resumen:}

La película Walesa, la esperanza de un pueblo (2013) constituye un ejercicio estilístico en el que a partir de una entrevista en profundidad se trenzan diferentes documentos audiovisuales para organizar un relato sobre la figura de Lech Walesa en forma de biopic. La teoría periodística relativa a la entrevista como género oscila entre la práctica informativa y el canon literario, este dilema permite trasladar al público, además de las palabras del entrevistado, la fugacidad de las impresiones ambientadas en un momento concreto, en un encuentro compartido por ambos. Una atmósfera que Andrzej Wajda utiliza para introducir la conversación que sostuvieron la periodista Oriana Fallaci y el líder de solidaridad Lech Walesa en 1980. Desde el domicilio de este último, explora una de sus obsesiones: el enigma del liderazgo social y su éxito frente a la adversidad.

\begin{abstract}
:
The film Walesa, the hope of a people (2013) is a stylistic exercise in which after an in depth interview different audiovisual documents are twisted to organize a story about the figure of Lech Walesa as a biopic. The journalistic theory on the interview as a genre ranges from the practical information and literary canon, this dilemma can move the public, besides the words of the interviewee, the transience of acclimated impressions at a particular time in a shared meeting by both. An atmosphere that Andrzej Wajda used to enter the conversation between the journalist Oriana Fallaci and Solidarity leader Lech Walesa in 1980. Since the domicile of the latter, explores one of his obsessions: the enigma of social leadership and success against the adversity.
\end{abstract}

\section{Palabras clave:}

Biopic; Wagda; Fallaci; Walesa; entrevista informativa; entrevista literaria; liderazgo.

\section{Keywords:}

Biopic; Wagda; Fallaci; Walesa; Informative Interview; Literary Interview; Leadership. 


\section{Introducción. De la entrevista al biopic}

El biopic político suele oscilar entre dos ejes narrativos: los conflictos entre la vida del protagonista, que el espectador va descubriendo con el film, y su discurso y acción política, que suelen ser conocidos con anterioridad. Sus reflexiones y dilemas frente a los conflictos, y por lo general sus sacrificios, personales o de su entorno, en beneficio del interés general o de la lucha que alimenta su liderazgo suelen conformar el carburante argumental que sostiene el relato. La película de Andrzej Wajda, Walesa: Man of Hope (2013) no es una excepción en este sentido. Sí lo es, en cuanto que se apoya en una única entrevista en profundidad y, desarrolla la trama, a partir de un momento crucial en la vida de su protagonista. El propio director al presentar su película en la Mostra de Venecia advertía sobre la dificultad que había encontrado para alcanzar esta solución. Este asunto merece, por tanto, una reflexión sobre la entrevista periodística como materia prima del relato biográfico.

El biopic se suele definir como la vida de un personaje mostrada por el celuloide. Con frecuencia, un personaje conocido y reconocido. Esparza y Parejo (2011, p. 13) sostienen una definición clásica del género como aquel que "tiene por objeto escenificar la biografía de un personaje famoso o parte de ella mediante un argumento verídico" y, observan, que los directores suelen bascular entre dos opciones: abordar, por un lado, la narración desde el género documental y, por otro, instalarse en la ficción desde hechos reales”. Ambas, aparecen en Walesa: Man of Hope

De la entrevista ha dicho Halperín (1995, p. 14) que es "la más pública de las conversaciones privadas”. Se entiende, por tanto, que el periodista es el autor de la entrevista y que el entrevistado conoce el eco que tendrán sus palabras. Ambos buscan un titular de alcance que haga atractiva la conversación para el lector, una sentencia que epate en la opinión pública. Así, Tim Martens de la BBC recoge las declaraciones de Lech Walesa después de presentar la película en Londres. "Soy un hombre de fe: sólo temo a Dios y a mi esposa”. 


\section{Una hipótesis recurrente: la trascendencia de la conversación}

Para llegar a la concepción moderna del texto que hoy entendemos por entrevista se ha recorrido un largo camino. En la búsqueda de sus antecedentes, López Hidalgo (1995, p. 83) se remonta a la antigüedad y fija el origen remoto de la entrevista en el diálogo como forma clásica de acceder al conocimiento. Busca un precedente más próximo en el periodismo americano: "el género de la entrevista ya se había instalado en diarios: primero tímidamente en el Boston Newsletter, a principios del 1700, con una serie de entrevistas sobre la muerte del pirata Barbanegra. Y un siglo más tarde con las entrevistas policiales del New York Herald y el London Morning Chronicle". Hoy son muchas las monografías sobre el tema: Frattini y Quesada (1994), Halperín (1995), Arfuch (1995), López Hidalgo (1997) o R. Betancourt (2001) Cantavella (2002), G. Huidobro (2005), entre otras. En todas ellas se abordan los aspectos teóricos más relevantes de la entrevista como género y se incide, en mayor o menor medida, en la dicotomía entre la entrevista informativa y la literaria.

En síntesis y, a partir de este conjunto de estudios, se puede entender la entrevista informativa como aquella que indaga de forma habitual en busca de nuevos datos, o la opinión del entrevistado, sobre un asunto de interés informativo. En la entrevista informativa el objetivo inicial del periodista consiste en informar a los lectores, en arrancar declaraciones exclusivas sobre la actualidad. Con este fin somete a un interrogatorio al entrevistado en busca de información inédita y centra su interés en la novedad o la polémica del momento. Este objetivo es determinante en la conversación y en la posterior redacción de la misma.

Por el contrario, en la entrevista literaria encuentra su objeto de interés en el conocimiento del personaje a través de la interpretación y la mirada del entrevistador. Las diferencias de ambas modalidades dependen, por tanto, de los objetivos que se persiguen con su publicación y, del lenguaje utilizado, tanto en la conversación como en la redacción final del texto. Así, de un personaje conocido nos bastan sus palabras, de un actor emergente, nos 
interesa su perfil. El recurso al lenguaje creativo permite presentar al entrevistado a partir de su propia visión del personaje, ofreciendo de él una imagen diferente. Se suelen intercalar declaraciones entrecomilladas, diálogos ingeniosos, preguntas inesperadas o momentos de tensión. Utiliza la descripción de forma explícita, alusiones el aspecto físico del entrevistado que en muchos casos definen estados de ánimo y rasgos de carácter. Se detiene en su entorno, en su forma de relacionarse con los otros y con las cosas. Indaga en su apariencia psicológica, en su comportamiento o su actitud conversacional. En fin, busca el retrato del personaje entrevistado. Como dice Luis García Montero es: "como un viaje a una ciudad extranjera en las que se comparan las realidades con las ideas que se llevan en la maleta”. Este tipo de entrevistas se sitúan, por tanto, en la frontera entre persona y personaje.

\section{De la teoría al periódico. Objetivos de la entrevista}

Oriana Fallaci, es la autora de la entrevista que da pie a la película, en la que traza con destreza el perfil de un nuevo y desconocido líder sindical Lech Walesa. Ella tiene su teoría al respecto y entiende la entrevista como un documento entre el periodismo y la historia, en el que busca la trascendencia de las palabras que permiten revelar el carácter del entrevistado, la condición humana de la persona que sostiene el personaje. Para la periodista italiana (1978, p. 9).

La historia de ayer es una novela llena de hechos que nadie puede controlar, de juicios a los que nadie puede replicar. La historia de hoy, no. Porque la historia de hoy se escribe en el mismo instante de su acontecer. Se puede fotografiar, filmar, grabar en cinta, como las entrevistas con los pocos que controlan el mundo y cambian su curso.

Cuando Fallaci acude a entrevistar a Walesa no conoce a la persona y, vagamente, al personaje. En esta dicotomía, Jozef Wlodzimierz, (2006) historiador y traductor al portugués de Kapuscinski, explicaba en una conferencia en la Universidad de Santiago de Compostela, la relación entre el conocimiento histórico y el trabajo periodístico: 
Lo que une ambos campos es la dependencia de la fuente, como condicionante de cualquier trabajo periodístico o histórico. En el caso del trabajo periodístico la calidad viene determinada por la actualidad de los trabajos producidos, que provoca evidentemente un stress y muchas veces obliga a sacrificar la profundidad de las cuestiones. El historiador, por su lado, no está presionado por el titular inmediato, pero en muchas ocasiones no dispone de fuentes directas.

Oriana Fallaci intenta cruzar la frontera entre ambas y revelar en sus fuentes su doble dimensión entre el personaje de actualidad y su trascendencia temporal.

No obstante, conviene ampliar algunas de estas circunstancias ya que los matices en este tipo de textos resultan decisivos y soportan en muchas ocasiones la singularidad de lo narrado. Así, García Huidobro (2005, p. 2) entiende la entrevista como un género ágil y vivo, que soporta múltiples esquemas y formas, a partir de un señuelo: la sensación del lector de asistir a la cita entre entrevistador y entrevistado. "Un sortilegio que hace olvidar que dicho encuentro es también una construcción de las palabras y de la estructura trabajada desde un texto". La entrevista debe trasmitir, por tanto, la magia del encuentro y hacernos pensar que las preguntas las hemos hecho nosotros mismos. Al comienzo de la película Andrezej Wajda subraya esta sensación y, no duda, en acompañar con su cámara a ambos protagonistas cuando acuden al encuentro. El espectador participa de la tensión del momento al acudir a un evento peligroso y, casi clandestino, privado y público a la vez, en el permanentemente vigilado domicilio de Walesa.

Una década después, Eric Frattini (1994, p. 138) explica como preparó su entrevista con el presidente Lech Walesa.

Hable con diversos periodistas polacos y con corresponsales extranjeros acreditados en Varsovia, que conocían bien al Presidente Walesa. Todos me decían lo mismo, si le interesa el tema de la entrevista estará mucho más tiempo contigo, si no le interesa te cortará en treinta minutos. Leí mucha información sobre el Presidente, entrevistas que le habían hecho y retratos escritos sobre él, lo que fue muy útil a la hora de sentarme ante Lech Walesa. 
En ese momento la entrevista suele responder a tres ítems: quién es el entrevistado; qué es el entrevistado, o, cuál es su actividad; y cómo es el entrevistado. También adquieren un protagonismo destacado el espacio en el que se desarrolla la entrevista y la coyuntura del momento. El lector busca en el texto la explicación, el porqué de la realización de una entrevista, es decir, la justificación por la cual se interpela a un personaje. Las circunstancias concretas que anteceden al hecho que motiva la entrevista y que lo acompañan, el dónde, cuándo y por qué de la entrevista. Eric Frattini (1993, p. 140) trazó en pocas líneas el perfil del personaje:

Lider sindicalista, Premio Nobel de la Paz, y Presidente de la República de Polonia, son algunas de las partes que conforman el retrato de Lech Walesa. El presidente aparece sumergido en un gran sillón, lo que hace que no se sepa bien que estatura tiene. Su cabello y su bigote comienzan a teñirse de blanco, según afirma el propio Walesa, entre risas, por razones del cargo y por razones de Estado. Su inglés es bastante deficiente, por lo que tras una disculpa me pide que usemos un intérprete de polaco e inglés. El Premio Nobel que se le ha concedido es algo ya muy lejano para él, aunque de vez en cuando conviene tenerlo presente para no perder la perspectiva de su cargo, ni el porqué del mismo. Él es una síntesis de sindicalista, Jefe de Estado, luchador por la libertad y por la paz y trabajador polaco... Él es Lech Walesa.

En la experiencia informativa diaria cuando un personaje público dice algo, de inmediato, los periodistas provocan una cascada de reacciones para que otros se pronuncien sobre la afirmación original. De esta forma la polémica arranca en la opinión pública generando por reacción muchas declaraciones que son meras interpelaciones en el debate público. En la actualidad, como explica Andrzej Wajda, el Walesa de la era postpresidencial sigue siendo una figura controvertida:

No es un individuo fácil de manejar. No le gusta quedarse con la boca cerrada. Todavía sigue activo en la escena política y en ocasiones dice algo complicado. Divide a la sociedad polaca entre la gente que sigue creyendo que es un héroe $\mathrm{y}$, otros, que piensan que es un traidor.

Oriana Fallaci también ha sido muy discutida, en especial, por su obra posterior al 11 de septiembre de 2001 hasta su muerte, el 15 de septiembre de 
2006. No obstante, Andrzej Wajda ha preferido situar a sus actores en un momento álgido de sus vidas y, crucial para el futuro de Polonia y de Europa.

Los entrevistados, en muchas ocasiones, sólo conocen lo que se dijo inicialmente a través de la versión que les traslada la prensa. Da lo mismo. La incontinencia verbal de algunos protagonistas y la voracidad de los medios para obtener declaraciones sobre cualquier asunto, es una de las claves que debe conocer el público para entender una parte, nada desdeñable de la actualidad diaria. En este sentido Walesa es impredecible y siempre concita la atención de la prensa, el ruido mediático acompaña al carismático líder.

La información publicada se convierte entonces en un juego de réplicas y contrarréplicas del que no escapa la entrevista. El profesor Héctor Borrat (1983, p. 128) entiende por tal, "el relato, publicado en el periódico, del diálogo sostenido entre dos o más personas, una de las cuales, asumiendo el rol periodístico de entrevistador, es su autor". Y afirma que, "en tanto que texto publicado, la entrevista convierte a la fuente con la que el periodista ha dialogado en actor de un relato informativo que puede asumir formas muy distintas, tanto en su construcción como en sus valores informativos", se trata de entender por entrevista únicamente el texto final publicado. Así, en su forma literaria trasciende el objetivo puramente informativo, se interpreta entonces como una obra de creación artística, en la que el autor, a partir de una conversación con el personaje entrevistado, recrea ese intercambio de preguntas y respuestas dándole una forma en la que lo imprescindible no es sólo qué dijo el personaje sino también cómo lo dijo, por qué lo dijo, qué podía estar pensando cuando lo decía, y qué quería decir en realidad. La entrevista en profundidad hace extensivo su interés a la propia personalidad del entrevistado, esforzándose además por ofrecer al público una pieza literaria acabada y completa.

La pluma de Oriana Fallaci (1978, p. 11) se sitúa entre las cumbres del género. Ella desvela sus temores al abordar una nueva entrevista.

El periodismo es un privilegio extraordinario y terrible, no es raro, si se es consciente, debatirse en mil complejos de ineptitud. No es raro, ante un encuentro importante, que sienta como una angustia, el miedo de no tener 
bastantes ojos, bastantes oídos y bastante cerebro para ver oír y comprender, como una carcomo infiltrada en la madera de la historia.

Frente al calculado esfuerzo informativo; esto es, claridad, sencillez, concisión, brevedad, búsqueda de la máxima objetividad. En el que se elude cualquier descripción accesoria sobre el entorno o, la personalidad del entrevistado, y que busca su ser en las propias palabras del sujeto. Suele limitarse a reproducir, en estilo periodístico, el cuestionario de preguntas y respuestas de la conversación. En la entrevista, como pieza creativa, aparece un lenguaje estético, que abunda en recursos literarios, incide en la enunciación y no sólo en el texto. Revela un retrato del entrevistado que permite ir más allá de sus palabras, de su tono, de sus gestos e, incluso, de la distancia que marque con el entrevistador. Con el paso del tiempo, como en el caso que nos ocupa, puede llegar a recrear una época, un carácter o un momento de la historia.

Oriana Fallaci (1970, p. 283) intenta ir más allá, trascender la actualidad, arrastrada por su curiosidad innata termina por incorporar a su vida personal a algunos de sus entrevistados. Ella se explica así:

Cuando era niña mi madre compraba la lana en madejas y luego hacía ovillos en ella. Y para formar el ovillo hacia una bola de papel, que podía ser blanco, un trozo de periódico, o la cuenta del tendero. De manera que siempre me consumía la curiosidad de saber y, mirando el ovillo cómo menguaba elaborando la pieza de punto, pensaba: ¿qué habrá metido dentro?

Como entonces, se enfrenta a los personajes y trata de descubrir el secreto que encierra la persona que oculta el personaje. Sus preguntas arrancan del interés personal, de una empatía que no oculta y, tira de sus textos.

Sus entrevistas a grandes líderes mundiales, en aquel momento Walesa no se encontraba entre ellos, fueron publicadas en Il Corriere della Sera y $L^{\prime}$ Europeo, y reproducidas en las principales cabeceras de referencia internacional. La mayoría han sido agrupadas y editadas en libros como Entrevista con la historia (1974) o Intervista con il Podere (2009), en este último se recoge su entrevista con Lech Walesa. Sus libros han sido reeditados y traducidos a muchos idiomas, su protagonismo en los mismos dieron a su autora, fama mundial. Oriana Fallaci (1978, p. 9) escribía para el 
presente y para el futuro. Y, se preguntaba de forma retórica: “¿la historia está hecha por todos o por unos pocos? ¿Depende de mil leyes universales o solamente de unos pocos individuos?”.

García Huidobro (2005, p. 3) sitúa la entrevista literaria en una "zona fronteriza donde se dan cita la historia, la crítica, la literatura, y los géneros del yo. Con todos ellos invadiéndose mutuamente e influyéndose de manera involuntaria”. A modo de rosa de los vientos, señala cuatro direcciones: al norte la historia; al sur la ficción; al oeste la autobiografía y al este el marketing. Una brújula muy práctica en la estima de la trascendencia en el tiempo de la conversación periodística y su correspondiente registro escrito. Entre estos vientos, Oriana Fallaci noveló su propia vida y, poco antes de entrevistar a Walesa había publicado Un hombre (1979), el relato en el que cuenta su relación con Alekos Panagulis, poeta y héroe de la resistencia griega que había muerto en misteriosas circunstancias tres años antes.

Oriana Fallaci (1978, p. 9) es un personaje reconocido por sus propios entrevistados, a los que disputa la palabra y rebate en la conversación. Una forma combativa de entender su quehacer profesional:

Dejo jirones del alma participo con aquel a quien escucho y veo como si la cosa me afectase personalmente o hubiese de tomar posición (y, en efecto, la tomo, siempre, a base de una precisa selección moral), y ante el entrevistado no me comporto con el desasimiento del anatomista o del cronista imperturbable. Me comporto oprimida por mil rabias y mil interrogantes que antes de acometerlos a ellos me acometieron a mí, y con la esperanza de comprender de qué modo, estando en el poder u oponiéndose a él, ellos determinan nuestro destino.

El uso cinematográfico de este tipo de entrevistas no es nuevo, aunque tal vez, en este caso, resulte relevante como la interpretación del personaje de la reportera adquiere, además un valor notarial del relato que aporta una suerte de auditoria externa que levanta acta del conflicto social que ha estallado. En palabras de la propia periodista italiana (1978, p. 13):

El juicio que un encuentro o un personaje nos ha merecido va haciéndose más amplio y profundo con los años. Pero, de haber sucumbido a la tentación de comentarlos conforme a la visual del tiempo, habrían perdido su valor de 
documentos cristalizados en el instante en que los vi y los presenté: su carácter de inmediatos se hubiese visto alterado cual una fotografía que se somete a retoques.

\section{Planteamiento y puesta en escena. Walesa: Man of Hope de Andrzej Wajda (Walesa. Czlowiekz nadzie, 2013)}

Andrzej Wajda nació en Suwalki, Polonia, en 1926. Hijo de una maestra y de un militar, durante la Segunda Guerra Mundial participó en la resistencia contra los nazis. Andrzej Wajda ha rodado medio centenar de películas desde 1954 y es una de las figuras más importantes del cine europeo. El cineasta polaco siempre ha sido crítico con lo que le rodea: sus historias retratan y cuestionan la de su propio país. Su obra ha sido reconocida con los máximos galardones: Palma de Oro del Festival de Cannes en 1981; el Premio César en 1983; cuatro veces candidato a la estatuilla de Hollywood obtuvo el Oscar Honorifico al conjunto de su carrera en el año 2000; Oso de Oro Honorifico del Festival de Cine de Berlín en 2006 entre otros. Fue director de teatro, director artístico del Teatro Powszchny de Varsovia; presidente de la Asociación del Cine Polaco entre 1978 y 1983. Entró en Solidaridad en 1981 y fue consejero del sindicato hasta 1989. Elegido senador de la República de Polonia entre 1989 y 1991. Miembro del Consejo de la Presidencia para la Cultura de 1992 a 1994 y del Institut de France. Numerosas universidades le han distinguido como Doctor Honoris Causa: Washington, Bolonia, Lyon, Libre de Bruselas, Jagiellonian de Cracovia, Gdansk y Varsovia.

Andrzej Wajda es, a su avanzada edad, el director europeo más veterano en activo. Con estos antecedentes, su película Walesa: Man of Hop sólo se podía estar fuera de concurso. Los festivales se disputan al director, y a sus protagonistas. Además de acudir a la Mostra de Venecia de 2013 llevó su película al Festival de Cine de Londres, al festival de Toronto y, a la sesión de clausura de la 58 edición de la Seminci de Valladolid. El film fue seleccionado para representar a Polonia en la categoría de películas de habla no inglesa en los Oscar de ese año. Llegó a las salas españolas el 1 de enero de 2014 con el título: Walesa: la esperanza de un pueblo que cierra la trilogía iniciada con 
El hombre de mármol (1976) y El hombre de hierro (1981), esta última con Lech Walesa interpretándose a sí mismo.

El director humaniza al Walesa cinematográfico a través de su esposa Danuta, interpretada por Agnieszka Grochowska. La personalidad del activista polaco quedará trazada además en la convivencia con sus hijos y su mujer. Frente a su familia muestra sus dudas, sus manías y defectos de andar por casa, como su coquetería o una buena dosis de egocentrismo. Muestra también su vocación de liderazgo, una suerte de fuerza que le empuja a la acción. Wajda desnuda a Walesa en su relación con la resignada Danuta, un matrimonio católico a la antigua usanza. El tiempo permite recuperar algunas anécdotas domésticas salpicadas de un singular sentido del humor, bastante surrealista. Wajda se explica y, se escusa, tras el pase en la Mostra:

No es mi sentido del humor, es el sentido del humor de Lech Walesa. Walesa no hubiera podido ser quién fue ni arrastrar a la gente con sus ideas si no hubiera sido por ese humor que llegaba a la gente en situaciones límite incluso con bromas bastante simples.

Wajda lo ha descrito como "el tema más difícil con que he tenido que trabajar" durante sus 55 años en el cine. "No me imaginé a ningún otro director haciendo una película sobre Lech con la que me hubiera sentido satisfecho. No tuve otra opción" declaró el director. Se conocieron en 1980, en la huelga que dio inicio a las revueltas en Polonia. Esa relación estrecha llevó a que Wajda conociera y trabara amistad con Danuta al comienzo de esta historia. La esposa de Walesa, uno de los grandes personajes casi silentes de su película, y a la que su marido, cada vez que sale de casa a destinos inciertos, le deja sus pocos objetos de valor mientras dice: "Véndelo si no regreso". "Era una persona que aceptó muy bien el papel de su marido, y a la vez cargó con la crianza de sus ocho hijos. Yo quería mostrar su actitud y su comportamiento". El largometraje reivindica la figura de Danuta y, su valor al acudir a Oslo a recoger el premio Nobel de la Paz en 1983, con el fin de evitar un más que posible destierro de su marido al salir del país. También, se detiene en la particular bienvenida que le brinda el régimen al regresar a Polonia con el preciado galardón. Un acontecimiento, por cierto, posterior a la entrevista que da origen al film. 
El crítico Juanma Cuellar destaca la propuesta de Wajda al vertebrar el desarrollo de la narración en torno a la conversación que mantienen el protagonista y Fallaci, será el "meta-relato" que aporta la condición biográfica con consistencia y credibilidad. Las películas, como las entrevistas, también pueden resultar fallidas: la verosimilitud es lo que cuenta, si el lector o el espectador no se integran en lo narrado, el resultado será baldío. La obsesión de su autora por entender las claves del liderazgo permite trasladar la tensión del relato y, tal vez, entender como un electricista del astillero de Gdansk puede llegar a alcanzar el Premio Nobel de la Paz y ocupar la Presidencia de Polonia.

El director marca la diferencia entre la imagen pública, en parte documental, y la historia del protagonista, con la introducción de algunos acontecimientos ficcionados dentro del propio film, con algunas anécdotas que aligeran el tono de la historia y la tensión de la propia entrevista. Ambos interlocutores tienen una fuerte personalidad y están acostumbrados a enfrentar momentos de tensión, esta se traslada a un cuestionario implacable cuyas preguntas revelan a un polaco católico, aferrado a sus convicciones, tan consciente de la limitación de sus capacidades como seguro de sí mismo. Se ilustra con una acumulación de apariciones públicas, que demuestran su instinto para interpretar el sentir popular y trasladar sus consignas a sus seguidores.

La película arranca contando la vida de Walesa cuando en 1970 las autoridades comunistas sofocaron las protestas de los trabajadores y Walesa se vio forzado a firmar un documento en el que acordaba convertirse en informante. Las escenas posteriores siguen su camino hacia la madurez política, el impacto que tuvo en su vida personal y en su relación familiar. Es la crónica de una desilusión, la de los trabajadores con el sistema que ayudó a provocar la caída del régimen. Wajda lo sintetiza como "una historia sobre trabajadores que tenía una visión diferente a la del Gobierno, que querían seguir sus reglas y no las reglas del Gobierno".

La actriz Maria Rosaria Omaggio, interpreta a Oriana Fallaci y explica a $\mathrm{Il}$ Giornale el carácter profético de la entrevista. La conversación va in crescendo a lo largo de la película. La actriz entiende que en aquel momento 
La Fallaci pasaba por una fase difícil, aunque era famosa en todo el mundo. Alekos Panagulis había muerto en 1976 y ella se había retirado a la Toscana junto a su madre, donde escribe Un hombre, un libro en el que relata sus recuerdos en primera persona. Superado el duelo se traslada a vivir a Nueva York. A pesar de las dificultades lingüísticas de la conversación en cierto punto de la entrevista, la negra sombra de Alekos se reencarna en Walesa. Ella entiende el futuro de persecución que espera al sindicalista igual que a su malogrado Panagulis. A medida que avanza su interrogatorio se convence que está ante ella un hombre decisivo para la suerte de Polonia y, del mundo entero. Ella comprende a lo largo de la entrevista que Walesa es la persona señalada. Por eso, la intensidad de Oriana cambia de escena en escena, creciendo en intensidad a lo largo de la película.

La trascendencia del encuentro no pasa inadvertida a su intuición.

En febrero de 1982, un año después la reportera viaja de nuevo de Nueva York a Varsovia para entrevistar al viceprimer ministro polaco Mieczylaw Rakowski, “¿recuerda el día en que nos conocimos aquí, en Varsovia, hace exactamente un año? Le acababan de nombrar viceprimer ministro y yo me dirigía a Gdansk (Danzig) para entrevistar a Lech Walesa. Le pregunte: “¿qué pasará si los soviéticos intervienen en Polonia?” Y me respondió: “todos los polacos se alzarían”. Entonces le volví a preguntar: “¿y qué sucedería si lo hiciera el mismo ejército polaco?”. Y usted me respondió: "lo aceptarían sin rechistar”.

Sobre estas mismas circunstancia recuerda Wagda: "fui el primero que le pregunté qué pasaría si llegaban los tanques soviéticos" como respuesta a las huelgas. "Walesa tuvo una gran seguridad, sin tener ninguna información, al decir rotundamente que no". Walesa entendió rápidamente que los tanques rusos no irían a Polonia y que las autoridades polacas no podrían hacer nada con el chantaje que trataron de aplicar en un primer momento a los obreros. El líder sindical entendió que la única forma era negociar e ir paso a paso”. En el otro bando, las autoridades no entendían al líder sindical.

El 13 de diciembre habían declarado la ley marcial, "advertimos al pueblo y a Solidaridad que, si continuaban la anarquía y los intentos de desintegración del estado, adoptaríamos medidas extraordinarias. Fallaci le responde: 
"sabíamos muy bien lo que sucedió en Hungría en 1956, en Checoslovaquia en 1968. Incluso ese día hace un año esperaba ver tanques soviéticos en las calles de Varsovia”. Rakowski cuenta su versión de los diferentes intentos de buscar una "conciliación nacional" y como siempre se topan con Walesa. "Y toda las veces le decía: "Es imposible, no escuchan. Yo abandono". Walesa declaró: "Es inevitable el enfrentamiento y lo tendremos. Las conversaciones no eran más que un truco; a partir de este momento veremos quién engaña a quién”.

Fallaci teme por la vida de Walesa e insiste, una y otra vez: "¿Cómo esta Walesa? ¿Qué va a hacer con él?

- Walesa está bien, muy bien. Vive en una casa a las afueras de Varsovia, donde dispone de tres cómodas habitaciones, y no se le trata como a un ciudadano de quinta categoría. Créame. Se le trata con mucho respeto, con todo el cuidado que requiere su posición sindical. Come bien lee los periódicos, ve la televisión, recibe visitas de su esposa, de sus hijos y de su hermano siempre que quiere, y mantiene contactos diarios con la gente de la iglesia, con monseñor Ursulich en particular. En realidad no está detenido. Está simplemente internado. Los juicios son únicamente por delitos cometidos durante: la ley marcial.

- Entonces, ¿̇por qué le mantienen internado en paradero secreto como si fuera un rehén norteamericano en Irán? ¿Por qué le mantienen aislado? ¿Por qué tiene viruela, o porque esperan convertirle en una especie de quisling, es decir, un colaboracionista, posiblemente con ayuda de la Iglesia?

- Le diré una anécdota de Walesa. El 4 de diciembre hubo una acción importante en Varsovia, algo que Walesa y los demás deberían haber tomado como una señal de que no estábamos bromeando cuando decíamos que estábamos dispuestos a emplear la fuerza. La milicia asalto la escuela de bomberos y puso fin a la ocupación. Esto sucedió a las diez de la mañana, y antes de las diez Stanislaw Closek fue a ver a Walesa, que estaba en un hotel, a informarle y mostrarle que estábamos jugando abiertamente. Walesa le respondió: "Bueno Closek, esto es el fin. Entonces tendremos que tomar el poder. Pero no se preocupe usted. Es usted un buen hombre. Le buscaré un empleo". 
- Le he observado mucho, su naturaleza de campesino me intrigaba. Igual que un campesino engañaba a su interlocutor, y nunca se podía encontrar un lenguaje común con él. En cierta ocasión, cuando estaba en este mismo despacho, le dije: "Walesa, ha conseguido muchísimo. ¿Por qué no se para consolidar lo que tiene? Descanse por un tiempo. Estas huelgas se le está yendo de las manos", y me respondió: "No, no, no necesito descansar. Me siento bien. No es tan malo como usted se cree". Pocas veces, como en esta entrevista, aparece tan nítido el enigma de liderazgo y su respuesta ante situaciones extremas. Una idea constante y que obsesiona a Oriana Fallaci: (1978, p. 12) "en la misma medida que no comprendo el poder, comprendo a quien se opone al poder, quien replica al poder, sobre todo a quien se rebela contra el poder impuesto por la brutalidad”.

\section{Aportaciones sobre el liderazgo: "alguien lo tiene que hacer"}

El biopic parte de la idea por la que solo en situaciones especiales surgen los héroes, aquellos que dan un paso al frente cuando al resto no sabe qué hacer. Andrezj Wajda encontró su pepita de oro en la empatía entre Oriana Fallaci y Lech Walesa. Las obsesiones de la escritora, su profundo conocimiento de los personajes y de la realidad polaca del momento, han permitido a dotar de unidad a la narración y, trasladar al film, la irrupción y el ímpetu de un nuevo liderazgo, de una nueva fuerza social. "Soy un hombre con una gran indignación interna, tengo las ideas claras. Soy como el toro que cuida el rebaño", confiesa a la periodista. Y explica Wajda: "puede que Walesa no fuera un hombre cultivado intelectualmente, pero poseía un carisma arrollador". Y en la charla con la periodista italiana, no solo se autodefinió como ese toro guardián. También aseguró: "las masas sin líder no tienen futuro". Y: "cuando la multitud se calla yo sé lo que tengo que decir". Con estas convicciones, más que argumentos, llegó a encabezar una corriente que fue seguida por diez millones de polacos y, que impacto en toda Europa.

En sus reflexiones sobre la imagen y el liderazgo, María Arnal (2012, p. 72) explica que un líder se nutre fundamentalmente de dos cuestiones: la historia de vida que ha tenido y la percepción que trasciende a los demás. Fallaci, descubre ambas en Walesa, un hombre sencillo, un líder sindical, un obrero 
de la resistencia alejado de los presidentes y jefes de estado a los que esta acostumbrada a tratar. En la estela que había definido Burns (1978):

El liderazgo es la acción de los líderes que induce a sus seguidores a actuar en pos de determinadas metas que representan los valores y las motivaciones los deseos y las necesidades, las aspiraciones y las esperanzas- tanto de los líderes como de los seguidores. Y el genio del liderazgo estriba en la forma en la que los líderes actúan en consonancia con las motivaciones y valores de sus seguidores y las suyas propias.

La idea puede resultar un tanto generalista, pero se trata de un concepto esquivo. No hay ningún conjunto de reglas o fórmulas a las que puedan atenerse los líderes. Sólo existen directrices y nociones genéricas, percepciones e ideas, abstracciones y generalidades. Ésta es la razón por la que la destreza para conducir personas se considere un arte y no existan modelos universales en el desempeño de la misión de decidir por un colectivo. En este caso, se trata de un hombre como los demás, en el que todos se ven reflejados, que se explica, de forma natural, que lidera desde la humildad, "no me harán nada soy un padre de familia numerosa", y que atesora muchas de las claves que son señaladas por los estudios biográficos del liderazgo como Philips (1993), Perkins (2014) o Krames (2015). Carismático, engreído, dotado de una oratoria subyugante, Walesa devino en mito al recibir el Premio Nobel de la Paz en 1983, pero su estrella decayó tras convertirse en Presidente del Gobierno Polaco en 1990.

Entre las muchas películas biográficas sobre líderes políticos las hay para todos los gustos. En la mayoría de los casos, intentan mostrar algún rasgo del protagonista, centrándose en la evocación del personaje, y por tanto, buscan la profundización psicológica del mismo. Algunas de ellas han sido utilizadas para explorar los mecanismos del liderazgo político. Otras buscan el retrato de una época, de un país o del grupo que acompaña al líder antes que mostrar otras cuestiones que pueden tener su interés para ilustrar las teorías del liderazgo, o bien sus cualidades para organizar redes y equipos. En esta Walesa reconoce, ante la cámara y en primer plano, su incapacidad para la gestión. Sin embargo, a inicios de los ochenta fue una de las burbujas que provocó la apertura de un hermético sistema político. 
En 1970 Wajda fue una de las personas que se acercaron a los astilleros de Gdansk cuando comenzó la huelga que lideraría Walesa y que sería el germen del movimiento libertario de su país. También, Robert Wieckiewicz, el actor que encarna a Walesa, recuerda, en Venecia ante los medios, que cuando era adolescente, en 1980, escuchó sobre la huelga del astillero de Gdansk en Radio Free Europe. Fue a Gdansk de vacaciones y recuerda "la atmósfera de libertad" de la ciudad portuaria del Báltico. "Podías decir cualquier cosa que quisieras sin censura. Por primera vez en mi vida pude respirar”.

El personaje, interpretado por Więckiewicz, mantiene su poder de fascinación y su condición de icono del fin de la "guerra fría". El actor protagonista, cuyo parecido es asombroso, representa a un Walesa tan carismático como contradictorio. Robert Wieckiewicz (6/9/2013) explica, en rueda de prensa, cómo abordó la interpretación del mito: "en la historia del mundo hay muchos íconos, como Mandela, que hicieron algo muy importante para otras personas en el mundo. Walesa es, en mi opinión, uno de ellos". El actor no estaba preocupado por interpretar a una figura sumamente conocida, alguien que además está vivo. "Walesa era como un hombre venido de Marte, un superhéroe. La gente lo entendía. Era uno de nosotros". Para mí se trata sólo de un hombre, un trabajador, un esposo y un padre. Por supuesto que es un líder, uno muy astuto, inteligente y ganador del premio Nobel. "Así que abordé este papel de la misma forma como cualquier otro. Leí el guion y traté de capturar los distintos niveles del personaje. Mi idea fue interpretar a "uno de nosotros". Éste es un punto de vista, aunque hay muchos otros. Su primer encuentro con Walesa se produjo en el pase de la película en la Mostra de Venecia. De hecho, aunque Walesa ayudó a la promoción de la película, mantuvo su distancia cuando ésta estaba siendo filmada: "no interferí y no quise involucrarme en la filmación". En cierta medida se trata de una biografía no autorizada filmada por un amigo y compañero.

Andrezej Wajda no duda en mostrar el paradójico liderazgo de Walesa y, subraya algunas secuencias de la película, con esta reflexión ante los medios:

Lo curioso es que Walesa lideró un sindicato que no fundó, aunque estaba allí desde sus inicios, cuando se acercó a sus oficinas a cantarles las cuarenta a sus 
líderes intelectuales, y que se hizo fuerte en la huelga que arrancó en el astillero de Gdansk el 31 de agosto de 1981. Walesa, que ya había participado en las protestas de 1970 -aunque intentado apaciguar a la gente-, hacía cuatro años que no trabajaba en esa factoría, pero se coló por un muro trasero y dio voz y rostro a aquel levantamiento.

Se trata por tanto de un liderazgo carismático que emerge ante la imperiosa dificultad de las circunstancias.

\section{Una reflexión subjetiva. Wajda y Walesa: el día después}

A la hora de clasificar los biopics se suelen diferenciar tres tipos de relatos. Aquellos en los que el director aborda la vida de una tercera persona. Un segundo tipo en el que coinciden narrador y biógrafo, Esparza y Parejo (1995, p. 14) los denominan autobiopics, y una tercera tipología, o falso biopic, en el que biografiado no existe, pero la intención de la película se encamina a evidenciar su autenticidad. El encanto del relato arranca de la vieja amistad entre director y protagonista y se detiene al narrar muchos de los acontecimientos vividos por ambos. Se sitúa, por tanto, a caballo entre las dos primeras opciones. Asi que, Wagda y Walesa se han divertido con el resultado final y en sus pases por diferentes festivales. En especial, con el proceso de desmitificación del héroe, con sus improvisaciones y la inexplicable intuición que guiaba sus decisiones.

Wajda y Walesa, 17 años más joven que el cineasta, han llevado vidas paralelas durante muchos momentos.

Es lo que ocurre cuando aúnas fuerzas contra una dictadura. Las autoridades fueron víctimas de su propia política. En 1980 ellos no querían hablar con los intelectuales, con los profesores ni conmigo. Solo querían negociar con un obrero porque se creían creadores de esa clase social. Y por tanto que podrían manipularle. Fue justo el haber crecido muy dentro del sistema comunista, lo que hizo que ese electricista tuviera las respuestas más poderosas. Yo conocí a Lech justo antes de que llegara la Comisión Gubernamental a negociar. Era arrebatador. 
Otros directores, algunos extraordinariamente longevos como Manoel de Oliveira, también han reflexionado sobre el binomio cine y memoria. El cine, nos viene a decir, es el medio en el que podemos revivir momentos del pasado. "Gracias al cine podemos volver a ver esos fragmentos". Agustin Gómez (2011:119) recoge algunas de sus anécdotas, “como que el montaje de su primera película lo hizo sobre la mesa de billar a mano directamente sobre los negativos". Se trata de un ejercicio personal y colectivo, de unir fragmentos de lo vivido y de la memoria, que es la que puede hacernos recordar. Andrezj Wajda participa también de esta visión cinematográfica de la vida. La memoria es siempre caprichosa dice su paisano Ryszard Kapuscinski (2/11/2003) y cuenta con ironía cómo su hermana extrañaba, pese a compartir los recuerdos, algunos de sus narraciones. Su diferente percepción sorprende y, divierte, al periodista de Pinsk. Algo similar le sucede a Walesa y, en el festival de Londres declara, después de ver al tozudo Lech en la gran pantalla: "he visto la película cuatro veces y cada vez me rio más”.

El día del estreno Walesa es una estrella de cine más en la Mostra de Venecia. María Luz Climent de La Vanguardia (5/9/2013) recoge su actitud frente a los acontecimientos:

Cada día me sentía más fuerte y más poderoso. Sentía que tenía que luchar, que seguir adelante. Claro que al principio todo el mundo siente medio, pero cuanto más tiempo está uno en lucha, menos temor se siente. $Y$ en realidad me gustaba esa sensación, y ahora que mi popularidad está de capa caída estoy buscando una nueva revolución que hacer.

Walesa, el electricista que hizo resquebrajarse el bloque soviético, reconoce que no tiene un carácter fácil, que le gusta bromear y que le aburre la política:

Tras media hora en el Parlamento empiezo a hacer crucigramas o a jugar con el ordenador", asegura con picardía. "Realmente no me gustan los políticos. Son aburridos y dicen cosas extrañas. Y aunque cambie de vida, tenía que reunirme con ellos y lo lamento. Por eso decidí no ser pesado y no solo narrar asuntos serios, sino bromear de tanto en tanto, porque la sociedad recuerda mejor las cosas y las absorbe mejor. Me aburrí tanto con esa gente que pensé 
que yo no iba a llegar a la gente si fuese como ellos. Claro está que resulta difícil inventarse esas bromas, pero como soy una persona sin una gran cultura, hago chistes sencillos.

En la actualidad el expresidente polaco Lech Walesa viste de forma informal, pero no falta en su camisa la medalla con el icono de la virgen. Walesa sigue siendo un enigma cuando se le pregunta qué piensa de la representación de su vida en la pantalla grande. "No tengo opinión. Voy a dejar que el público saque sus propias conclusiones". ¿Qué tan difícil fue equilibrar su vida como hombre de familia y como activista político? "Fue muy duro porque siempre quise ser el mejor. No estoy seguro si lo logré. Nací para ser el número uno". "No me arrepiento de no haber pasado más tiempo con mi familia porque he vivido mi vida hasta el máximo y no puedo lamentarme del pasado". Walesa, sonríe. "Soy un hombre de sorpresas", dice. "Así es como gané. Sorprendí a los comunistas, sorprendí a Yeltsin, sorprendí a muchos presidentes". Y después, tras una pausa, agrega: "también he tenido mucha suerte".

Las acotaciones realistas son obligatorias en un relato histórico, pero también una mezcla de grises en un escenario al que muchas veces precede la leyenda. A esto se suma la peculiar complejidad de un personaje que evoluciona de la sencillez del electricista a las alturas del líder que domina la estrategia y la puesta en escena, capaz de improvisar golpes de efecto sin pestañear. Pero ¿cómo liberar al gran icono de su imagen y retratar al ser humano? Wajda responde: "lo importante es que cuando Lech tuvo que ser crítico con la realidad, lo fue”. En Walesa, el estilo del realizador se aleja de imposturas estéticas. Utiliza iluminaciones naturalistas y las secuencias con cámara al hombro se alternan con imágenes documentales de la época para coser la ficción a la realidad con la autenticidad de las referencias históricas. La banda sonora compuesta por Paweł Mykietyn agiliza con eficacia el montaje y pega el desarrollo narrativo a la condición realista sin perder velocidad. En resumen, Wajda logra un relato lleno de matices que se apoya en un guion clásico y, todo ello, a partir de una única entrevista en profundidad.

Lech Walesa, cierra el círculo de la influencia mutua y afirma que las películas de su compatriota les ayudaron "a seguir luchando". "Sin sus 
películas no hubiera sido capaz de hacer lo que hice". "Wajda siempre ha tenido una visión profética en su cine y ha intentado mostrar a los jóvenes cómo acabar con un sistema". Una película hecha desde la necesidad de narrar lo vivido y que cree en la capacidad trasformadora del séptimo arte. Es otra forma adentrarse en "la jungla polaca" de Kapuscinski y de luchar por la dignidad. Wajda, se despide: "espero haber hecho una película para que la gente se pregunte: ¿quién es el héroe de nuestro tiempo?, ¿dónde podemos encontrarlo?, ¿de quién podemos seguir el ejemplo?".

\section{Conclusiones}

Andrzej Wajda rodó Walesa: Man of Hope (2013) a los 87 años. Se trata de un relato épico en el que rinde homenaje al líder polaco y reivindica su papel en la caída del régimen comunista. El director polaco se sirve de la entrevista que Oriana Fallaci realizó a Lech Walesa en 1980 para trenzar un biopic en el que el retrato periodístico del personaje sirve para hilvanar la narración de unos acontecimientos decisivos para toda Europa.

La elección del director no es casual y permite trasladar al espectador alguno de los arcanos que explican el liderazgo de Lech Walesa y su irrupción en la opinión pública internacional. La entrevista elegida por Wajda responde literalmente al singular hacer de Oriana Fallaci, convirtiéndose, junto a sus hijos y su esposa Danuta, en una más de los protagonistas del film.

La larga conversación no es una más de la periodista italiana, es una experiencia singular para sus protagonistas. Redactada con vocación historicista permite al director narrar unos hechos decisivos para la historia de Polonia y de toda Europa. También eludir otros acontecimientos y posiciones posteriores, menos relevantes, en la vida de sus protagonistas y en el devenir político internacional.

Andrzej Wajda ha realizado una cuidadosa elección que la ha llevado a engarzar los mimbres con precisión, incluidas imágenes de la época, durante más de una década de trabajo, y que permite acceder al relato biográfico desde la óptica puntual de la entrevista. El ímpetu del carismático liderazgo de Lech Walesa le lleva a protagonizar múltiples episodios, no exentos de un 
singular sentido del humor, que ejemplifican una forma de entender la acción política y las relaciones personales. Un estilo, que el director ha querido reconocer y, ha sabido llevar al biopic, desde el momento crucial de una entrevista histórica.

\section{Referencias bibliográficas}

Arfuch, L. (1995). La entrevista, una invención dialógica. Barcelona: Paidós. Papeles de Comunicación.

Arnal, M. (2012). Iron Lady. Reflexiones sobre la imagen y el liderazgo. Málaga: Fotocinema, $\mathrm{n}^{\mathrm{0}} 4$.

Borrat, H. (1983). El periódico, actor político. Barcelona: Gustavo Gili.

Bernal, S. y Chillón, L. A. (1985). Periodismo informativo de creación. Barna: Mitre.

Burns, J.M.G. (1978). Leadership, New York: Harper \& Row.

Cantavella, J. (2002). Historia de la entrevista en prensa. Madrid: Universitas.

Climent, M.L. (6/9/2013). "Si me hubieran escuchado hace 20 años no estaríamos así". Barcelona: La Vanguardia.

Cuellar, J. (31/12/2014). "Lech Walesa en el cine, la Historia de un hombre frente a la Historia". Madrid: RTVE.

Dennis, N.T. Perkins (2014). Lecciones de liderazgo. Las 10 estrategias de Shackleton en su gran expedición antártica. Madrid: Desnivel.

Esparza, R. y Parejo, N. Coords. (2011). Solos ante la cámara. Biopics de fotógrafos y cineastas. Barcelona: Luces de Gálibo.

Fallaci, O. (1970). Nada y así sea. Barcelona: Noguer.

Fallaci, O. (1978). Entrevista con la historia. Barcelona: Noguer.

Fallaci, O. (1979). Un hombre. Barcelona: Noguer.

Fallaci, O. (28/2/1982). Mieczyslaw Rakowski: "La sangre hubiera corrido a ríos en Polonia si no hubiéramos declarado la ley marcial el 13 de diciembre". Varsovia: El País.

Fallaci, O. (2/3/1982). Mieczyslaw Rakowski: "A Walesa no se le trata como a un ciudadano de quinta categoría”. Varsovia: El País.

Fallaci, O. (2009). Intervista con il Potere. Milano: Rizzoli.

Frattini, E (1994). Lech Walesa en FRATTINI, E y QUESADA, M. La entrevista. El arte y la ciencia. Madrid: Eudema.

García de francisco, A. (31/12/2014). "Lech Walesa dice que el cine de Andrzej Wajda nos ayudó a seguir luchando". Venecia: EFE INT. 
García Huidobro, C. (2005). Los puntos cardinales de la entrevista literaria. Caracas: Analítica.

Gnocchi, A. (22/8/2013). Walesa visto dalla Fallaci: "Fu un "intervista profética”. Venecia: il Giornale.it

Gómez, A. (2011). "Lecciones autobiográficas del maestro Oliveira", ESPARZA y PAREJO, Solos ante la cámara. Barcelona: Luces de Gálibo.

Halperín, J. (1995). La entrevista periodística. Intimidades de la conversación pública. Buenos Aires: Paidós.

Iborra, J. R. (2002). Confesionario. 25 Entrevistas a escritores. Barna: Ediciones B.

Kapuscinski, R. (2004). O Imperador. Porto: Campo das Letras.

Kapuscinski, R. (2006). Viajar con Heródoto. Barcelona: Anagrama.

Kapuscinski, R. (2008). La jungla polaca. Barcelona: Anagrama.

Krames, J. (2015). Liderar con humildad. Barcelona: Alienta.

López Hidalgo, A. (1997). La entrevista periodística. Entre la creatividad y la información. Madrid: Ediciones Libertarias.

Masters, T. (22/10/2013). "Lech Walesa: Sólo temo a Dios y a mi esposa". Londres: BBC.

Montero, R. (1996). Entrevistas. Madrid: El País-Aguilar.

Ocaña, J. (31/12/ 2014). “Los orígenes del mito”. Madrid: El País.

Phillips, D.T. (1993). Lincoln y el liderazgo. Bilbao: Deusto.

Quesada, M. (1984). La entrevista, obra creativa. Mitre. Barcelona.

Quinque, P. (6/11/2013). "El fundador de Solidaridad denuncia que faltan líderes”. Caracas: El Pensador.

Rodríguez Betancourt, M. (2001). La entrevista periodística y su dimensión literaria. Madrid: Tauro.

Sánchez dragó, F. (2/11/2003). Negro sobre blanco, Oviedo: RTVE.

Wlodmierz, J.S. (1/3/2006). A inspiraçao histórica no trabalho jornalístico de Ryszard Kapuscinski. Conferencia, Santiago de Compostela, Inédita.

Cómo citar: Galindo Arranz, F. (2015). "De la entrevista al biopic. Andzej Wajda, Walesa: Man of Hope (2013)". Fotocinema. Revista científica de cine y fotografia, 11, pp. 3-25. Disponible: http://www.revistafotocinema.com/ 